Vol. 73, N. ${ }^{\circ}$ II7 (mayo 202I), 59-77

ISSN-i I390-6380, ISSN-e 2697-3332 | https://doi.org/I0.29I66/economia.v73iII7.26I9

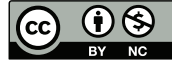

\section{LA VIOLENCIA EPISTÉMICA EN LAS CIENCIAS ECONÓMICAS: PANDEMIA, CONFUSIÓN EPOCAL Y EXTRAVÍO EN EL MAR CAUDALOSO DE LOS PROBLEMAS PÚBLICOS}

\author{
EPISTEMIC VIOLENCE IN THE ECONOMIC SCIENCES: PANDEMIC, EPOCHAL \\ CONFUSION AND LOSS IN THE MIGHTY SEA OF PUBLIC PROBLEMS
}

\author{
ISAAC ENRÍQUEZ PÉREZ \\ El Colegio Mexiquense, A. c. (México) \\ Recepción manuscrito: 28 de septiembre de 2020 \\ Aceptación versión final: $1 .^{\circ}$ de abril de 2021
}

RESUMEN En medio de la confusión epocal, se pretende reivindicar el ejercicio del pensamiento crítico en la ponderación de la epistemología propia de la teoría económica neoclásica. Los problemas económicos contemporáneos que gestan rupturas históricas, imponen desafíos teórico/epistemológicos a dicha teoría, y ésta - al encontrarse desanclada de ellosno siempre brinda las respuestas pertinentes respecto al proceso económico que afecta al ciudadano de a pie. Al problematizar a la pandemia como un hecho social total dotado de sistemas complejos, se evidencia la resistencia de esta teoría al ejercicio de la interdisciplinariedad y al diálogo con otros campos del conocimiento en aras de privilegiar el estudio de la sociedad como totalidad.

palabras ClaVe Teoría económica neoclásica, violencia epistémica, interdisciplinariedad, decisiones públicas, pandemia.

ABSTRACT In the midst of the epochal confusion, it is intended to vindicate the exercise of critical thinking in the weighting of the epistemology of neoclassical economic theory. Contemporary economic problems that breed historical ruptures, impose theoretical / epistemological challenges to said theory, and this theory - because it is disengaged from them-does not always provide the pertinent answers regarding the economic process that affects the ordinary citizen. By problematizing the pandemic as a total social fact endowed with complex systems, the resistance of this theory to the exercise of interdisciplinarity and dialogue with other fields of knowledge is evidenced in order to privilege the study of society as a whole.

KEYWORDS Neoclassical economic theory, epistemic violence, interdisciplinarity, public decisions, pandemic.

Jel Codes A2, A11, A12, A14, B41. 


\section{INTRODUCCIÓN}

Las ciencias económicas - especialmente las cultivadas y difundidas a lo largo del siglo xx y principios del siglo XXI- no solo son un discurso académico, aparentemente neutral, dotado de un sofisticado y especializado lenguaje, y ataviado mediante la modelización matemática. Son, también, un conjunto de significaciones y referentes teórico/epistémico/ético/ideológicos y una serie de prescripciones respecto a la realidad social que inciden - directa o indirectamente, en mayor o menor medida, y a la par de intereses creados- en la representación de la realidad, la construcción del poder, el ejercicio de la dominación y en la toma de decisiones públicas. De estos referentes teórico/normativos se desprenden pautas normativas y prescriptivas que modelan cursos de acción, comportamientos y procesos o estrategias de intervención en la realidad y en sus problemáticas. De ahí que, en principio, no sean ciencias neutrales ni objetivas como se precian de serlo las ciencias físicas, sino que son disciplinas interesadas al estar preñadas de cosmovisiones y rasgos axiológicos, éticos e ideológicos. Ello es así pese a la soberbia y pretendida superioridad de los economistas respecto a otras formas de conocer lo social humano.

En ese sentido, cabe argumentar que no existe una teoría económica monolítica, sino que existen múltiples y distintas teorías económicas que bien podrían complementarse las unas a las otras; aunque sea una de ellas la que se erige en el mainstream, en la corriente hegemónica que tiende a subsumir y ningunear al resto tras perfilar su estatus de supuesta superioridad científica a partir del sofisticado manejo del lenguaje matemático. También cabe puntualizar que lo económico no remite, exclusivamente, a la relación coste/beneficio, ni al trapicheo o a la simple acción de compra/venta; actos regidos, se diría, por la racionalidad ilimitada del Homo œeconomicus. Es más que ello: remite a múltiples formas de organización de la sociedad para satisfacer las necesidades humanas más elementales tras proveerse los medios de vida. Y en ello no solo converge una racionalidad instrumental, sino múltiples racionalidades que le dan forma a la naturaleza del ser humano en sociedad.

A partir de lo anterior, cabe plantear algunos interrogantes que le dieron sentido a la investigación que subyace en el presente texto: ¿Por qué las ciencias económicas -especialmente la teoría económica neoclásica- evidencian un desanclaje o distanciamiento respecto a la lógica de la realidad social contemporánea? ¿En qué consiste la violencia epistémica y cómo incide en la mirada y posicionamientos del economista convencional de cara a la incertidumbre y complejidad de las problemáticas contemporáneas? ¿Por qué las ciencias económicas convencionales se resisten, en medio de su autismo, al ejercicio de la investigación interdisciplinaria y al diálogo abierto con otros campos del conocimiento a partir de objetos de estudio que se conforman como sistemas complejos? ¿Por qué la teoría económica convencional no logra aprehender los rasgos, cauces y magnitudes estructurales de las crisis del capitalismo contemporáneo? ¿Cuáles son los rasgos ideológicos de esta tradición de pensamiento que se anteponen a la comprensión cabal de las crisis económicas? De este modo, el objetivo principal de nuestra investigación consistió en construir y posicionar un discurso analítico en torno a las contribuciones, alcances, inconsistencias y limitaciones de las ciencias económicas en torno a su 
labor de comprender y explicar el sentido y las contradicciones de las sociedades contemporáneas y de sus problemas públicos. A la par de ello, se trata de comprender cómo estas cegueras en el conocimiento propio de las ciencias económicas inciden en la toma de decisiones y en la hechura y ejercicio de las políticas públicas.

En el curso de la investigación realizada, se perfiló una premisa teórico/metodológica crucial que es necesario enunciar: los problemas públicos contemporáneos conforman sistemas complejos dotados de interrelaciones e intensas interdependencias endógenas y exógenas; de ahí la relevancia de apelar a la investigación interdisciplinaria para tender los puentes entre las ciencias económicas y otros campos del conocimiento sobre lo social humano. Sin ese diálogo interdisciplinario, no solo se perfilan perspectivas fragmentarias y dispersas de la realidad social, sino que el inducido autismo de disciplinas como la economía también incide en la manera en que son concebidos los problemas públicos, se toman las decisiones y se diseñan las posibles soluciones. En esta incapacidad para observar y comprender a cabalidad los problemas contemporáneos, subyacen en la teoría económica neoclásica limitaciones epistemológicas que se tornan cegueras del conocimiento, así como la tendenciosidad ideológica propia de los profesionistas que abrazan los supuestos restrictivos inspirados en la escasez, el individualismo metodológico y la racionalidad ilimitada del Homo œconomicus. Sin un mínimo diálogo multidireccional, es tarea cuesta arriba la comprensión cabal de la lógica y el sentido del comportamiento humano y de las relaciones sociales en las cuales intervienen los agentes socioeconómicos. Como consecuencia de estas cegueras del conocimiento, se anteponen formas preconcebidas de observar la realidad, así como formas de pensar en torno a las posibles estrategias de intervención. De ahí la emergencia y expansión de una especie de violencia epistémica que entroniza significaciones y narrativas que evidencian algunas aristas de los problemas públicos y silencian, encubren e invisibilizan otras. El tratamiento de la pandemia y de la crisis económica que le acompaña no es la excepción a esa lógica.

\section{EL DISTANCIAMIENTO DE LA TEORÍA ECONÓMICA CONVENCIONAL RESPECTO A LOS PROBLEMAS CONTEMPORÁNEOS}

La realidad social contemporánea es una vorágine de hechos, acontecimientos y procesos entrelazados e intergenerados que discurren con intensidad por múltiples cauces interdependientes que conforman sistemas complejos y estructuras dotados de dinamismo, densidad e incertidumbre. Las sociedades humanas representan una totalidad cuya estrecha articulación entre sus partes integra distintas modalidades de praxis - entre ellas, la relativa al proceso económico- que responden a distintas racionalidades y formas de posicionarse ante la realidad social. Este carácter sistémico e interdependiente no está exento de la exposición a las crisis y a la emergencia de fenómenos que trastocan sus fundamentos y alejan a la sociedad del equilibrio y la armonía.

Pese a sus incapacidades predictivas y a sus limitaciones teóricas para explicar una gran cantidad de fenómenos - tales como el subdesarrollo, la desigualdad extrema global, la injusticia social, la pobreza, el hambre, las recurrentes crisis del capitalismo, la insuficiencia de crecimiento económico, el desempleo masivo, las epidemias, entre otros- que afectan la vida 
cotidiana de los ciudadanos, la teoría económica convencional adolece de la arrogancia, jactanciosidad y autocomplacencia de quienes la ejercen académica y profesionalmente. Revestidos con el aura de la cientificidad objetivista (para mayores detalles véase Enríquez Pérez, 2008 y 2016b), encubren, invisibilizan y tergiversan el carácter histórico de la praxis económica; las relaciones de poder que subyacen en el proceso económico; las condiciones de explotación como génesis de la desigualdad económica; las contradicciones de la ilusión del progreso; el carácter consustancial o inherente de las crisis en el capitalismo; la contradictoria y depredadora relación sociedad/naturaleza y el colapso climático; las epidemias como fruto de la depredación de la dimensión ambiental de la existencia social; así como la génesis de las guerras internacionales y los conflictos intestinos. Como estas convulsiones y contradicciones sociales se tornan disruptivas ante la prevalencia del modelo del equilibrio económico general, suelen obviarse e invisibilizarse o, a lo sumo, son encapsuladas en explicaciones que no se contraponen a los supuestos neoclásicos.

Más aún, persisten varias inadecuaciones entre la teoría económica convencional y los hechos históricos. De tal modo que, como corriente principal, hace de sus supuestos un dogma incuestionable e inmutable que se antepone a la realidad para predecir el comportamiento humano. Por ejemplo: el autismo de la teoría económica convencional reincide en el tratamiento de la pobreza desde una óptica cuantitativa y paliativa; al tiempo que obvia la explotación, la exclusión social, la estratificación y las relaciones de poder consustanciales al capitalismo. Incapaz de predecir y explicar la crisis económico-financiera del 2008-2009, los representantes de esta profesión que entronizan su discurso en los mass media, instalan, en este 2020, la idea de que la pandemia del coronavirus SARS-COV-2 provoca la crisis de la economía mundial. Culpar a un minúsculo patógeno (León Rodríguez, Gómez Corral y Castro Ponce, 2020), novecientas veces menor al ancho de un cabello y con una letalidad del $1 \%$ - los distintos tipos de cáncer causan, anualmente y a nivel mundial, la muerte de 9,6 millones de personas-, de una más de las manifestaciones de la crisis estructural del capitalismo, no solo es irresponsable, sino falto de toda honestidad y de mínima validez, cientificidad, rigor metodológico e historicidad. Esto es, tal como lo argumentamos en otro espacio, la crisis epidemiológica global se incubó en la misma crisis sistémica y ecosocietal del capitalismo (Enríquez Pérez, 2020).

Los economistas convencionales no cuentan con respuestas mínimamente estructuradas respecto a los grandes tópicos temáticos de su disciplina. Y no por falta de pericia técnica o por ignorancia - aunque no son pocos quienes la padecen y les lapida la imaginación creadora-, sino por la obstinación ideológica que subyace en sus supuestos y que, como gremio profesional, los posiciona en una situación de falso confort e insularidad que les desconecta de diálogos fructíferos con profesionistas de otras disciplinas.

Que en sus teorías se equivoquen, no solo es un asunto de incumbencia estrictamente académica e intelectual, sino que tiene implicaciones sociales en la medida que su disciplina incide en las decisiones públicas y en los cursos de acción. Esto es, el tratamiento de este tema no es baladí, pues el trabajo de los economistas convencionales - especialmente de aquéllos cercanos a las decisiones públicas y al poder- no rinde frutos en cuanto a las soluciones que esperan los ciudadanos respecto a los problemas públicos más acuciantes. Ello significa que las poblaciones padecen los efectos negativos de las prescripciones fundamentadas en supuestos 
infundados que se pretenden universales y carentes de mínimo trabajo histórico-empírico respecto a las especificidades de los problemas públicos y a las diferencias y singularidades en las forma de vida entre una sociedad y otra. Por ejemplo, si se prescribe la austeridad fiscal en economías nacionales con escenarios recesivos, serán severos los impactos en la caída del crecimiento económico, el empleo y de los indicadores de «combate a la pobreza». Más lo serán en sociedades que experimentan crisis institucionales. Incluso, en el mismo contexto de la pandemia, es muy probable que sea un economista convencional el que susurra al oído de algún tomador de decisiones y sugiere sendos paquetes presupuestales de «rescate» para salvar de la quiebra inducida a las grandes corporaciones y bancos, bajo el supuesto infundado de que ello revertirá la crisis económica y preservará los empleos de la clase trabajadora.

El supuesto de la escasez es una coraza mental que enclaustra a quien lo proclama en los márgenes de dilemas restrictivos, sin consideración de las dimensiones institucionales, simbólicas e históricas de la realidad social. El mundo fenoménico no se rige por la lógica de opciones binarias - como el decidir entre el producir mantequilla o cañones (argumento de Samuelson y Nordhaus, 2006), y menos cuando se trata de decisiones geoestratégicas orientadas a la expansión de las hegemonías nacionales en el sistema mundial-, sino que toda decisión en el proceso económico está mediada por relaciones de poder, mecanismos de estratificación social, estructuras de dominación y exclusión, y por convencionalismos culturales que refuerzan estos rasgos.

\section{LA VIOLENCIA EPISTÉMICA Y EL ENCUBRIMIENTO E INVISIBILIZACIÓN}

DE LA REALIDAD SOCIAL COMO TOTALIDAD

En sus pretensiones de cientificidad, la teoría económica neoclásica se enmarañó en las prioridades propias de las técnicas administrativas y de la gestión. Aunado ello a que esta teoría económica suele preocuparse más por la psicología modelizable del consumidor y del empresario, que por el sentido y lógica del proceso económico en su conjunto y como praxis con dimensiones históricas y arraigada en instituciones y relaciones de poder. Regida por el supuesto de un Homo œconomicus imaginario, ahistórico, eterno, desanclado de la dimensión territorial-ambiental, y dotado de una supuesta racionalidad ilimitada, la teoría económica convencional se extravía en las arenas movedizas de la era de la incertidumbre. Este enfoque teórico de la ciencia económica, en sus modelizaciones, hace del ser humano un cyborg ahistórico y mercantilizado que compra, vende y maximiza ganancias sin restricción alguna, como si no existiese el poder, lo político, el sentimiento, lo simbólico, lo poético, lo lúdico, el derroche, lo artístico, lo religioso, la compasión, y las decisiones y comportamientos irracionales que nos alejan de un pensamiento instrumentalista. De ahí su autismo y su violencia epistémica.

La noción de violencia epistémica o cognitiva remite a un discurso profundamente relacionado con las estructuras de poder — sea en el ámbito de la toma de decisiones o en entre las comunidades académicas - que gesta significaciones y formas de representar la realidad social y sus problemáticas tras privilegiar ciertas racionalidades y no otras que se ubican al margen de ese poder - sea intelectual, político o simbólico-. Esta violencia epistémica está en función del sujeto investigador o de las comunidades académicas que, sobre la base de consensos, 
despliegan su poder cognitivo y contribuyen a la construcción de imaginarios sociales respecto al comportamiento y cauces que adopta la realidad. A través de este discurso, se asume que el conocimiento y, particularmente, la teoría representan un mecanismo de construcción de poder que condensa y orienta las cosmovisiones, concepciones, prioridades, pautas de comportamiento y acciones de quienes se acercan a sus fuentes para encontrar respuestas en torno al comportamiento de la realidad social. Como discurso preñado de dosis de poder, tiende a silenciar, invisibilizar, encubrir y ningunear formas de vida y de organización social específicas que son asumidas como ajenas, distintas y distantes y, por tanto, incomprendidas y reducidas a lo inexistente o marginal — sería el caso de las racionalidades alternativas de la economía social y solidaria, del Buen Vivir o de la comunalidad (véase, por ejemplo, Enríquez Pérez, 2018; Acosta, 2013 y 2014; Gasca Zamora, 2014) - . El etnocentrismo (para una reflexión amplia sobre este fenómeno intelectual, véase Enríquez Pérez, 2009b) es el eje rector de este discurso y, en la medida que la racionalidad instrumental occidentalizada se posiciona, el carácter universal de sus postulados, tesis y supuestos axiológicos y normativo-prescriptivos es entronizado en la explicación e interpretación de la realidad social y en la subsunción, invisibilización y segregación de las especificidades, la diversidad, la interculturalidad, las alteridades, las identidades y las formas y estilos de vida asentadas en espacios locales. Con esos conceptos, categorías, sistemas teóricos y supuestos explicativos y axiológicos perfilados en el norte del mundo y, principalmente, desde las universidades globales y sus agendas de investigación, se nutren cosmovisiones, significaciones y simbólicas dotadas de valores absolutos, atemporales o ahistóricos, con pretensiones universales, y distantes de los rasgos sui géneris propios de las territorialidades locales/regionales/nacionales. Este etnocentrismo se alimenta también de la reproducción acrítica que se realiza con vehemencia - desde el sur del mundo- de voces anglófonas, francófonas o germanas como modernidad, progreso, libertad, democracia, justicia, cambio social, revolución, riqueza, desarrollo, bienestar, mercado autorregulado, escasez, competencia perfecta, Estado de derecho, entre otras.

La violencia epistémica no se limita a esta invisibilización, silenciamiento, negación y segregación de aquellas formaciones sociales y culturas distintas y distantes de los valores y cosmovisiones occidentales, sino que también se extiende a las significaciones y concepciones diseñadas y difundidas por entidades como los organismos internacionales (véase, por ejemplo, el caso del Banco Mundial en Enríquez Pérez 2009a, 2010b, 2014, y 2016a) y las agencias de planeación de los gobiernos nacionales. Nociones como desarrollo sostenible (ONU), desarrollo humano (PNUD), pobreza absoluta (BM), estabilidad macroeconómica y abatimiento de la inflación (FMI), entre otras, al tiempo que gestan códigos de comunicación entre las agencias nacionales de planeación y los funcionariados internacionales, crean en el imaginario social una percepción etnocéntrica estandarizada y homogénea en torno al tratamiento de los problemas públicos en las sociedades subdesarrolladas.

En suma, un ejemplo de esta manifestación de la violencia epistémica o cognitiva es el relativo al tratamiento de la dialéctica desarrollo-subdesarrollo (véase Enríquez Pérez, 2017). La teoría y política del desarrollo - especialmente la de manufactura anglófona- irrumpe en el escenario de la academia y en el propio de la toma de decisiones como un discurso que pretende reformar las estructuras de poder, dominación y riqueza, sin comprometer los cauces 
mismos del proceso de acumulación de capital y los mecanismos de estratificación social que tienden a perpetuarse y a reproducir las desigualdades. De ahí la necesidad de un discurso dotado de significaciones que apuesten a la homogeneización en la explicación e interpretación de la realidad social, así como en la construcción de pautas éticas, normativas y prescriptivas para gestar un lenguaje técnicamente operativo y traducible en directrices de políticas públicas, que no siempre toma en cuenta las facetas específicas de los distintos territorios e identidades de las sociedades subdesarrolladas. En la construcción de este discurso dotado de violencia epistémica, la ciencia económica en su vertiente neoclásica —especialmente la economía del desarrollo convencional- desempeña un papel crucial al crear y difundir lenguajes que entronizan una forma particular de concebir y tratar los problemas públicos; al tiempo que se desconocen y ningunean aquellos estilos de vida, racionalidades y formas de organización social alternativos y orientados a satisfacer las necesidades humanas básicas.

Así lo fue desde la formulación e irradiación de las teorías de la modernización con su noción de desarrollo como un continuum que se materializa en la sociedad moderna o de consumo de masas como cúspide de la linealidad histórica y acumulativa anclada a la idea clásica de progreso. Y así se extiende hasta las concepciones del desarrollo humano, el enfoque de las capacidades, las teorías del capital social, o los enfoques poskeynesianos (para mayores detalles, véase Enríquez Pérez, 2010a). Predomina en estas teorías del desarrollo una perspectiva etnocéntrica de la historia y de la naturaleza humana, ataviada con una ideología anglicana y liberal que entroniza el individualismo metodológico y que asume al bienestar social como resultado de la sumatoria de los bienestares atomizados. Estos discursos teóricos lo mismo se replican al interior de las universidades que en organismos internacionales como la Organización de las Naciones Unidas (ONU), el Banco Mundial (BM), el Programa de las Naciones Unidas para el Desarrollo (PNUD), la Comisión Económica Para América Latina y el Caribe (CEPAL), entre otros.

Más aún, la violencia epistémica emanada de la ciencia económica convencional se manifiesta en el comportamiento y dinámica propios de la división técnica del trabajo científico. En la compartimentalización de los saberes y de las disciplinas se despliegan mecanismos de estratificación académica donde predomina la vanidad intelectual que imprime una especie de desdén, desprecio y marginación respecto a aquellos saberes y conocimientos que brindan luz sobre las otredades, la alteridad y las racionalidades alternativas (sobre la racionalidad empresarial alternativa, véase Enríquez Pérez, 2018). Pensemos en los estudios culturales, la antropología del desarrollo, la ecología política, los estudios orientales, los estudios latinoamericanos, los estudios africanos, el Trabajo Social, la etnohistoria, los estudios de género, la sociología de las emociones, la filosofía de la liberación, la sociología de la explotación, los estudios decoloniales, entre otros, y a los cuales se les niega y desconoce por su aparente ambigüedad identitaria y por no alcanzar un estatus de cientificidad similar al de las ciencias físico-naturales imitadas por la ciencia económica convencional.

Esta violencia epistémica puede cancelar toda posibilidad para aprehender a la realidad social como una totalidad orgánica, como un mar de sistemas complejos interrelacionados que, para su comprensión, ameritan de la convergencia de múltiples saberes y de la construcción de conceptos y categorías interdisciplinarios que contribuyan a desentrañar el sentido de los rasgos sui géneris de las sociedades subdesarrolladas. 
El mayor pedigrí de las ciencias económicas respecto a otros campos disciplinarios se relaciona con su cercanía al poder y con su proclividad a contribuir al proceso de toma de decisiones y al tratamiento de problemas públicos nacionales o mundiales. Ataviado ello con el manto de la objetividad y de la pretendida cientificidad a partir de la modelización matemática de sus postulados y supuestos. Sin embargo, detrás de la cientificidad como fin último, subyace un entrelazamiento con el pensamiento parroquial alejado del rigor analítico y de la interpretación ponderada filosófica y metodológicamente.

Ante un mundo incierto y plagado de laberintos que conducen al desconcierto, representantes de la corriente principal de las ciencias económicas como Richard B. Freeman, docente de la Universidad de Harvard, señalan que en el crecimiento de una economía nacional, «la suerte parece tan importante como la política económica» y que la riqueza o la pobreza de los individuos «lo que es la desigualdad», dentro de un régimen de competencia de mercado, está en función de la habilidad, el esfuerzo o la suerte, si se cuenta con una dotación inicial justa de capital físico y humano; en tanto que las redes de seguridad social provistas por el Estado tendrían un carácter secundario (Freeman, 1996; otro texto que retoma el tema de la suerte en el análisis económico y donde participa el mismo autor es el editado por Lazear y Shaw, 2018). Si la relación no siempre tersa entre la eficiencia económica y la equidad se finca en la suerte, se pierde de vista el carácter contradictorio de esta relación y se obvia su construcción sociohistórica y la lógica estratificada de las sociedades capitalistas. Apelar a la suerte como explicación última de las problemáticas y conflictividades económicas es más un artilugio ideológico para encubrir las relaciones de poder y dominación que subyacen en el proceso económico y en el mercado.

Más todavía, naufragando en la resignación tras apelar a la suerte, la teoría económica convencional se parece más a las «ciencias ocultas» que a la sistematización y el rigor metodológico en la construcción del conocimiento científico. A su vez, ello demuestra que la historia del pensamiento económico sintetiza las disputas ideológicas que subyacen en los arreglos sociales en torno a la distribución de la riqueza y a la intervención del Estado en la vida social. La teoría económica convencional, en este sentido, es fruto de una correlación de fuerzas ideológicas cercanas al poder, sea académico o político, y que deambulan en la ficción, el misticismo, el autismo y la unilateralidad vaciada de mínimo sentido común.

Cabe señalar también que la teoría económica neoclásica es la expresión más acabada de la praxis científica que encubre su ideología para construir poder e incidir en las decisiones públicas. En ello es crucial negar, encubrir, invisibilizar y silenciar vastas porciones de la realidad social que remiten a las contradicciones del capitalismo y que desestabilizan la modelización econométrica sustentada en los supuestos de la escasez y de la competencia perfecta.

Más aún, para trascender esta violencia epistémica o cognitiva resulta pertinente recurrir al fecundo trabajo intelectual propio de los estudios de la descolonización del saber y que desde una óptica latinoamericana muestran una certeza crítica a las limitaciones de las ciencias sociales occidentales. La perspectiva decolonial — que puede ser complementaria a esta noción de violencia epistémica - se apoya en las contribuciones de autores como Enrique Dussel, Aníbal Quijano, Edgardo Lander, Arturo Escobar, Walter Mignolo (2000), Fernando Coronil y Ramón Grosfoguel (2005 y 2011). Desde Canadá y desde el activismo indígena, Leanne Betasamosake Simpson introduce la noción de extractivismo cognitivo para remitir a una actitud ante el 
conocimiento y con la cual se niega el diálogo horizontal de saberes; esto es, el conocimiento occidental asimila y subsume los conocimientos, cosmovisiones o cosmogonías de los pueblos autóctonos hasta despolitizarlos, vaciarlos de su sentido original, alternativo y radical, y sustraerlos de su lengua nativa (Klein, 2013; Simpson, 2014). Al no entender los saberes y conocimientos autóctonos en su propio sentido y lógica, entonces son extraídos, expoliados y resignificados desde una lógica etnocéntrica por los organismos internacionales o las universidades globales para colonizarse y tornarlos funcionales en la epistemología y cultura propia del norte del mundo. Estas nociones e ideas científicas, medicinales, ambientales, operativas, técnicas o tecnológicas y tradicionales, tras ser expoliadas o despojadas, pasan a formar parte de la acumulación de capital o de los circuitos académicos globales que las tornan poder y capital simbólico al gestar una narrativa particular en torno a los problemas públicos. Acercar estos debates a la investigación, docencia y difusión de la teoría económica convencional sería una labor crucial para abonar a la comprensión más amplia del proceso económico. No menos importante sería la apertura respecto a otras perspectivas Por último, sería necesario trabajar como otras tradiciones y perspectivas como la propia de la economía social, solidaria y popular, de la economía feminista, de la economía de la vida y de los cuidados, o incluso de las llamadas economías plurales.

\section{ESCASEZ, INDIVIDUALISMO METODOLÓGICO Y EQUILIBRIO COMO SUPUESTOS RESTRICTIVOS DE LA TEORÍA ECONÓMICA NEOCLÁSICA QUE INHIBEN LA INTERDISCIPLINARIEDAD}

Obsesionado por el equilibrio y por la eficiencia de mercado, el análisis económico convencional antepone el dogma de la competencia perfecta porque sin estabilidad es imposible sostener sus modelizaciones econométricas. Obviando con ello el conflicto social, la(s) desigualdad(es) extremas, el carácter disruptivo de las crisis, y la(s) violencia(s) que subyace(n) en el proceso económico y en la acumulación de capital; así como el desequilibrio consustancial al comportamiento y dinámica del capitalismo. Esto es, la contradicción y el cambio social —mas no el equilibrio defendido por una economía neoclásica, que parece más una economía termodinámica o una termodinámica de la economía-, son, desde esta perspectiva teórica, los rasgos fundamentales del proceso económico que resultan obviados.

El aislamiento de los economistas convencionales y la creencia de que su ciencia es exacta y más rigurosa y científica que otras, no solo abren un foso con la misma realidad, sino con la posibilidad de emprender diálogos interdisciplinarios con miras a apoyar las decisiones relativas a los problemas públicos. Interesados estos profesionistas en pequeños y acotados problemas susceptibles de modelización matemática — regida por el supuesto infundado y sin realismo de la escasez (léase Enríquez Pérez, 2016b) - tras descontextualizarse de las relaciones de poder, de las instituciones, del análisis histórico y del razonamiento fundamentado en la epistemología, terminan por no brindar respuesta a los grandes, inmediatos y cotidianos problemas sociales en torno a los cuales preguntan, y angustian, a los ciudadanos de a pie. Este desanclaje de la realidad está en función de la entronización de supuestos restrictivos que se orientan más a intentar predecir que a explicar con realismo el comportamiento de los hechos, fenómenos y procesos económicos. 
Este carácter restrictivo de los supuestos económicos se relaciona con su talante arbitrario, su rigidez, su limitado realismo y su carente contrastación histórico-empírica. Alejados de las condiciones de incertidumbre que se tornan disruptivas ante las pretensiones de armonía y equilibrio en las sociedades contemporáneas, los supuestos de la teoría económica hegemónica asumen a los agentes económicos como autómatas que eligen y actúan en un vacío institucional e histórico, guiados obcecadamente por los imperativos del costo-beneficio y los propios de una racionalidad ilimitada maximizadora de las ganancias desplegada en condiciones de escasez. El énfasis de su acción social es puesto en la fase de intercambio y no en el conjunto del proceso económico y en la producción como punto de partida, como bien lo perfiló Karl Marx en la Introducción general a la crítica de la economía política de 1857 en tanto expresión del método dialéctico de «elevarse de lo abstracto a lo concreto».

Con ello, el análisis económico convencional, al apoyarse en generalizaciones y modelizaciones fundamentadas en supuestos restrictivos y premisas infundadas que pretenden predecir, más que explicar, obvian las relaciones sistémicas y estructurales que rigen a los hechos económicos y al conjunto del proceso económico. Y aunque desde este enfoque se abordan - en una especie de psicología de las decisiones empresariales y del consumidor- las preferencias de los agentes económicos, no se muestra una vocación por analizar e interpretar su génesis y la manera en que se construyen históricamente. Al obviarse las instituciones y las relaciones de poder, los modelos económicos corren el riesgo de generar una representación artificial de la realidad, así como análisis incompletos, inconexos, sesgados y equivocados. Al predominar una metodología (neo)positivista, empírico-analítica y objetivista, preñada del individualismo metodológico - la sociedad como sumatoria mecánica de individuos atomizados al estilo de Robinson Crusoe- y del método del instrumentalismo predictivo (tal como lo definió Boland, 1997) de Milton Friedman (1953) mediante el cual los modelos econométricos fundamentados en la notación matemática — que obvia el carácter de las relaciones sociales y de los entramados institucionales como arreglos que condensan relaciones de poder y que le dan forma a los mercados - son antepuestos al comportamiento del contradictorio mundo fenoménico y de sus problemáticas en el seno de las sociedades capitalistas. Para esta mirada pragmática de la ciencia económica, no es importante que los supuestos sean o no realistas con miras a validar, contrastar empíricamente y brindar coherencia epistemológica a las teorías y modelos económicos. De lo que se trata es de perfilar al conocimiento científico como un instrumento útil - mas no verdadero ni falso - para el control de la realidad y la gestión y resolución de problemas propios de la política económica. El pragmatismo instaurado por la Escuela de Chicago se fundamenta en la construcción de la validez de los modelos a partir del consenso en el seno de las comunidades académicas de economistas que se compenetran con la matriz económica neo-positivista. De ahí que no se privilegie la verificación de las hipótesis, sino la refutación al estilo del falsacionismo popperiano. Lo relevante es la formulación de conclusiones que parten o abrevan de teorías, hipótesis y modelizaciones, que solo se consideran válidas y dotadas de coherencia lógica si logran predecir correctamente los hechos económicos o si éstas predicciones se corresponden con la experiencia y el mundo fenoménico (Friedman, 1953). Entonces se presenta una tensión entre la economía como ciencia objetiva - que privilegia el estudio del ser - y la economía como ciencia pragmática — que, inspirada 
en pautas normativas preñadas de rasgos ideológico-políticos, axiológicos y éticos-, estandariza miradas sobre el deber ser y construye significaciones para moldear decisiones e intervenir en el curso de la realidad. Al gravitar la tendenciosidad ideológica en la construcción de la teoría económica, conduce al sujeto investigador a formular ciertas preguntas de investigación y no otras; a analizar ciertos hechos económicos y no otros, aunque estuviesen frente a su mirada incisiva. De ahí que se corra el riesgo de silenciar, invisibilizar, encubrir y ningunear aquellas facetas de la sociedad que salen de los márgenes de las anteojeras ideológicas y de los supuestos restrictivos preñados de ello. Esta faceta prescriptiva de la ciencia económica convencional converge con el perfil ingenieril del economista, especialmente en un ámbito como la macroeconomía (sobre el economista como científico o como ingeniero, véase Mankiw, 2006), que es sustraída del análisis sistémico y estructuras y vista como una extensión o prolongación de los hechos microeconómicos.

En la epistemología de la teoría económica convencional, la explicación — que consiste en abstraer y simplificar la realidad a través de hipótesis - y la predicción del comportamiento y resultados de los fenómenos que se desconocen son simétricas o equiparables en el marco del despliegue de la llamada economía positiva. Si la predicción de hechos económicos desconocidos o sin observar por parte del investigador es la prioridad de la teoría económica, entonces no es relevante que los supuestos sean distantes de la realidad o que la contradigan (Friedman, 1953). Y si ello ocurre y se generaliza, entonces al esbozar sus conclusiones y generalizaciones la ciencia económica hegemónica corre el riesgo de erigirse en un artilugio especulativo y cuasiteológico vaciado de todo referente histórico-empírico. De ahí que los supuestos restrictivos y faltos de realismo sean más un mecanismo para la gestación de una identidad y cohesión teórica y profesional al interior de sus comunidades. Esa misma identidad distancia de los diálogos interdisciplinarios y refuerza la propensión a la violencia epistémica o cognitiva.

En esta forma de construir el conocimiento científico se impone una epistemología fragmentaria, compartimentalizada, individualista y mecanicista. Y esto coincide con el mismo postulado de Milton Friedman que enuncia que la única responsabilidad social de la empresa consiste en incrementar sus ganancias (Friedman, 1970) y que ello precisa de menor Estado, de nulas o débiles regulaciones y de masivas reducciones de impuestos. La praxis económica se disloca, con estos argumentos, de la praxis política; y este distanciamiento no solo se gesta en el plano de la teoría económica y del debate ideológico que le es consustancial, sino también en el propio de la vida pública y del diseño de la política económica. Lo que priva en esta ideologización de la teoría económica convencional es la idea de que las relaciones sociales son asumidas como un escenario de competencia y eficiencia económica, en tanto que los ciudadanos son concebidos como consumidores movidos por preferencias y expuestos a sanciones de mercado si incurren en fallos e ineficiencias. En esta ideología, la planeación estatal es la causa de los problemas públicos. Y con ello se abona a la consigna tatcheriana — tan en boga durante la década de los ochenta - que proclama la inexistencia de la sociedad y la entronización de los individuos por encima de ésta.

Lo anterior se refuerza con la perspectiva del descriptivismo esbozada por Paul Samuelson desde finales de la década de los cuarenta. Esto es, la notación matemática es asumida como el lenguaje principal del análisis económico convencional con miras a afianzar la pretendida 
objetividad en la construcción del conocimiento científico dentro de la economía. La frase mentes frías al servicio de corazones ardientes (Samuelson y Nordhaus, 2006, p. 6) remite justamente a esta perspectiva que le da forma a la epistemología objetivista e hipotético-deductiva. La misma transición hacia una teoría económica matematizable y regida por las abstracciones dejó atrás el carácter implícito de los modelos econométricos y los erigió en un lenguaje explícito que, por el contrario, tornó implícitas las relaciones. En ese trance, fueron omitidas las instituciones, la praxis política y la construcción sociohistórica del proceso económico. Así, el lenguaje matemático no es más un instrumento auxiliar, abreviado o condensado. Además, se pierde de vista que no es el fin último en la construcción de la teoría económica; sino que al privilegiar el objetivismo, el lenguaje matemático no logra aprehender el carácter densamente contradictorio de las sociedades contemporáneas expuestas al vértigo de la incertidumbre y a la alta conflictividad social que, en su conjunto, escapan a todo rasgo epistemológico lineal, absoluto, mecanicista y universalista. Si se impone el lenguaje matemático a la densidad teórico-conceptual, entonces se amplían las posibilidades de la tergiversación semántica y de un desdibujamiento de los conceptos y categorías de análisis que no logran aprehender las especificidades de las relaciones sociales. Más aún, se impone la tecnificación del conocimiento por encima del rigor analítico y el papel de la lógica y la coherencia filosófica en el ejercicio del oficio de la investigación. Entonces la elegancia de los modelos y de la economía matemática no sustituye la densidad epistemológica ni el ejercicio del pensamiento crítico en la misma construcción de la teoría económica y en el análisis del capitalismo y sus problemas estructurales contemporáneos.

El distanciamiento de la teoría económica convencional respecto a la interdisciplinariedad se suscita también por el monismo metodológico y la proclividad de las comunidades académicas de economistas a entronizar la noción de que «solo existe lo que es medible». La metodología hipotético-deductiva y las pretensiones de objetividad al estilo de las ciencias físico-naturales se convierten en un mantra, en un corsé epistemológico que limita el diálogo de saberes con otros campos del conocimiento de las ciencias sociales que recurren a metodologías como las propias de las sociologías comprehensivo-interpretativas o de los postulados de la teoría social crítica de orientación marxista que privilegian, en el caso de esta última, un análisis histórico-estructural sobre las tendencias y contradicciones del capitalismo.

En última instancia, el proceso económico no solo es material; es también jurídico, político, simbólico-cultural, territorial, temporal, institucional, organizacional, dotado incluso de rasgos religiosos y de múltiples códigos de comunicación y significaciones. Es, pues, un sistema complejo dotado de interrelaciones entreveradas que, con mucho, desbordan el simple intercambio de bienes y servicios o la compra/venta de mercancías reducida a una relación monetaria empresa/consumidor.

Más que predecir con la teoría económica y el ejercicio probabilístico todo aquello que se asume como mensurable, lo que importa es reivindicar la explicación como ejercicio central en la construcción del conocimiento científico en la economía; y articularlo con las labores y los posicionamientos epistemológicos descriptivo-analíticos, comprehensivo-interpretativos, axiológicos, éticos y normativo-prescriptivos que muestran relaciones orgánicas y fronteras frágiles.

Para estos economistas - formados en el paradigma de las universidades anglosajonas-, el mercado - la intersecación automática de las curvas de la oferta y la demanda- y su soberanía, 
es el principal mecanismo para asignar los recursos y para ordenar las relaciones sociales. Contraria a la economía política clásica y a la crítica de la economía política, que fundaron sus obras en la necesidad de comprender los fenómenos económicos con el fin de explicar de mejor forma el conjunto de la sociedad, la teoría económica convencional se pretende aséptica y distante del resto de las ciencias sociales, en tanto que su objeto de estudio es concebido como una ínsula desanclada del resto de las relaciones sociales. Tergiversando y vaciando de sentido la metáfora de la mano invisible introducida por Adam Smith en su obra fundacional La riqueza de las naciones, esta modalidad de ciencia económica reniega de las funciones económicas del Estado y del papel de las instituciones en la procuración de la equidad social. Abriendo con ello falsos dilemas que agrietan la historia del pensamiento económico, así como el diseño y ejercicio de la política económica: ¿Estado o mercado?; o, bien, ¿más Estado o más mercado en la vida social? ¿Inflación o pleno empleo? ¿Gasto público o austeridad fiscal? ¿Eficiencia económica o equidad social? Estos falsos dilemas son, esencialmente, dilemas dados por los juicios de valor y por la tendenciosidad ideológica que predominan entre quienes los plantean. Solo es posible escapar de esa trampa dicotómica si hacemos un esfuerzo colectivo por comprender la dialéctica desarrollo/subdesarrollo a partir de asimilar el carácter sistémico de la relación Estado (política)/mercado (economía) y la urgencia de complementariedad entre ambos en el concierto de la proyección, estabilización y legitimación del capitalismo como modo de producción y como proceso civilizatorio.

Respecto a esos falsos dilemas, cabe señalar también que la utopía del mercado autorregulado es la eterna entelequia que la ciencia económica convencional pretende justificar para omitir la relevancia de la praxis política y las funciones estratégicas del Estado relacionadas con la distribución de la riqueza y con el carácter contradictorio del progreso. En ese debate que, a su vez, es ético y político, se juega la tensión entre justicia social y el carácter excluyente y desigual que signa al capitalismo.

A grandes rasgos, el dogmatismo y la fe en una ciencia económica unificada y aparentemente homogeneizada por el lenguaje matemático, conduce a ningunear otras miradas en torno a los problemas contemporáneos, en aras de legitimar un sistema económico y un proceso (des)civilizatorio que, en sí mismo y al soltarse a las libres fuerzas del mercado, tiene en sus entrañas la exclusión, la desigualdad, la opresión, la depredación de la naturaleza, la emergencia de territorialidades subdesarrolladas y la ausencia de democracia real. No solo la economía mundial contemporánea está en crisis, sino también lo está la ciencia económica que le estudia sin gran capacidad para desentrañar su esencia, comportamiento y problemáticas en distintas escalas territoriales.

\section{LA PANDEMIA COMO COARTADA PARA INVISIBILIZAR LA CRISIS SISTÉMICA Y ECOSOCIETAL DE LARGA DURACIÓN}

No solo invadida por la introspección y el autismo que corroe sus entrañas y le aleja de otros saberes y disciplinas, la teoría económica convencional — nos referimos a la neoclásica proveniente de las escuelas anglosajonas de economía, negocios y finanzas- es rebasada por el devenir incierto y volátil de los acontecimientos históricos y se muestra incapaz de explicar el 
origen y comportamiento de las crisis económicas contemporáneas, así como del colapso del capitalismo acelerado con la pandemia del covid-19. Esta teoría económica alcanza un nivel de sofisticación tal, que olvida, premeditadamente o no, estudiar la realidad social como una totalidad orgánica y atender sus dimensiones histórico-geográficas, simbólico-culturales, jurídico-políticas, etc.

En otro espacio, se esbozó la noción de que la pandemia es un hecho social total que, al estar dotado de sistemas complejos, tiende a reconfigurar profundamente las relaciones sociales, las instituciones, las estructuras socioeconómicas, las prácticas y relaciones de poder, los cotidianos estilos de vida e incluso la intimidad de individuos y familias (Enríquez Pérez, 2020). Más aún, la pandemia es la manifestación contemporánea, con sus respectivos impactos de larga duración, de una crisis sistémica y ecosocietal que, concretamente, tiene su génesis con la crisis estructural del capitalismo en tanto proceso de larga duración gestado — desde la década de los setenta del siglo xx - con el agotamiento del patrón de acumulación taylorista/ fordista/keynesiano y del mismo modelo de crecimiento económico ilimitado. Como parte del colapso civilizatorio contemporáneo, la pandemia es un macroproceso inédito -incluso un macroexperimento de control social- acelerador de un cambio de ciclo histórico de amplias proporciones que lo mismo remite a la ruptura de las cadenas globales de valor, producción y suministro tras echar a andar el confinamiento global; la intensificación del avasallamiento de la clase trabajadora; la radicalización de la desigualdad extrema global ante la emergencia de nuevos náufragos o víctimas; al cambio en el patrón energético y tecnológico; al agravamiento de las contradicciones en la relación sociedad-naturaleza, con la depredación, el ecocidio y el colapso climático como principales factores de destrucción del medio natural y de la eliminación de las fronteras entre el ser humano y el resto del reino animal; la irradiación de un depredador sistema agroalimentario industrial que lo mismo afecta la salud humana que al medio natural; la reconfiguración de las relaciones económicas y políticas internacionales, con sus correspondientes reacomodos geopolíticos y geoeconómicos en el corto y mediano plazos y con la radicalización de la crisis de la cooperación internacional; la transformación de las funciones del Estado - con el consecuente retorno al Estado hobbesiano - y el colapso en la legitimidad de sus instituciones fundamentales; la incapacidad de los tomadores de decisiones para prever y hacer frente a la crisis epidemiológica global; la emergencia de nuevas formas de autoritarismo y hasta de totalitarismo apoyadas en el higienismo, en tanto nueva ideología estatal, la biopolítica, la bioseguridad, la biovigilancia, la geolocalización y las posibilidades que abren para ello las tecnologías de la información y la comunicación; al debilitamiento y desmantelamiento sistemáticos de los sistemas sanitarios tras imponerse el dogma de la disciplina fiscal; la lapidación de la palabra en medio de la proliferación de la desinfodemia, la conspiranoia y la construcción mediática del coronavirus; al miedo, la incertidumbre y el social-conformismo como sensaciones que trastocan la intimidad y la cotidianidad y que, incluso, redefine la vulnerabilidad, los rituales y la postura ante la muerte; entre otras expresiones.

De ahí que como hecho social total (noción esbozada desde la sociología y la antropología Mauss, 1924, 1950), la pandemia se encuentre dotada de múltiples sistemas complejos articulados y conformados de relaciones orgánicas que perfilan la emergencia de nuevas estructuras sociales y la reconfiguración profunda de las existentes y construidas históricamente. Todo 
ello abrirá cauces a rupturas y crisis epistemológicas que trastocarán — cuando desde las ciencias sociales nos enteremos de la magnitud- las formas de concebir y pensar la realidad social y las problemáticas contemporáneas. Aunque también radicalizará la orfandad ideológica y la crisis de sentido (sobre esta última noción, véase Furedi, 2003; Enríquez Pérez, 2010a) que postra y hace caer en la resignación a las élites políticas e intelectuales y al conjunto de las sociedades contemporáneas en sus posibilidades de imaginar el futuro y de construir proyectos alternativos de organización de la vida social.

Por tanto, la pandemia coloca a la humanidad ante una doble crisis: una crisis epistemológica que remite a los límites que impone a las formas de pensar la realidad, y una crisis política que evidencia la incapacidad de las sociedades - y, particularmente, de los Estados - para proyectar su devenir y para construir decisiones que, más allá de los paliativos, contribuyan consistentemente a la resolución de los grandes problemas mundiales. El tema no es baladí, pues ambas crisis —obviadas por la teoría económica convencional- se interrelacionan para darle forma al colapso civilizatorio que se cierne desde décadas atrás y del cual la crisis sistémica y ecosocietal forma parte y se magnifica con el confinamiento global. Entonces, se impone la necesidad y la urgencia de remover los velos que encubren, invisibilizan y silencian esta amalgama de crisis multidimensionales y la génesis y causalidades de las mismas.

Moneda común a lo largo del 2020 es atribuir —desde la industria mediática de la mentira y sus corifeos académicos del pensamiento económico hegemónico- que el coronavirus SARS-COV-2 es el causante de la actual crisis económico-financiera mundial y la caída del crecimiento económico en múltiples economías nacionales. En realidad, estos fenómenos, que ya se expresan en el comportamiento de indicadores macroeconómicos referidos a los últimos meses y que le dan forma a proyecciones estadísticas, no se gestan con la pandemia, sino con las medidas de confinamiento global que propician la caída de la demanda de los consumidores y en la ruptura de las cadenas de producción y suministro piloteadas por las redes empresariales globales.

La penetración masiva de esta visión e interpretación cuasiteológica propia del pensamiento parroquial que acostumbra difundirse desde la teoría económica neoclásica y enfatiza en supuestas causas sobrenaturales, ahistóricas y hasta relacionadas con la suerte o el azar, erige un discurso reduccionista que traza significaciones descontextualizadas y carentes de análisis epistemológico e histórico, que, en última instancia, se afianza para legitimar - y no cuestionar desde el ejercicio del pensamiento crítico- las estructuras de poder, riqueza y dominación.

El coronavirus SARS-COV-2 no solo no es el causante de la crisis económico-financiera que afecta a la economía mundial, sino que ese agente patógeno es resultado de la misma degradación del patrón de acumulación fundamentado en la depredación y destrucción de la dimensión ambiental de la existencia social, así como de la misma noción etnocéntrica del progreso y del agotamiento del modelo de crecimiento económico ilimitado. La crisis económico-financiera de este 2020 es una manifestación más de la crisis estructural y de larga duración del capitalismo, detonada, cuando menos, desde la década de los setenta y acentuada con las decisiones públicas, corporativas y mediáticas que le dieron forma a la gran reclusión, en tanto proceso sociohistórico inducido para reestructurar al capitalismo en sus fundamentos, en sus prácticas y en sus procesos de acumulación y para apuntalar la reconfiguración de 
las hegemonías en el sistema mundial a partir de la traslación del poder global de la cuenca del Atlántico a la cuenca del Pacífico.

Se pierde de vista, además, que los virus y las bacterias son parte consustancial de la convivencia del ser humano con la naturaleza, así como de la adaptación y coevolución de los organismos vivos. Sin estos agentes patógenos, son imposibles los equilibrios ambientales y sanitarios. Y, por tanto, el organismo humano es resiliente a sus efectos y termina por adaptarse en el tiempo a la presencia e impactos de esos virus. De ahí que las pestes, las plagas, las epidemias y las gripes sean fenómenos históricos, construcciones sociales, relacionados en su génesis y manifestaciones con la contradictoria y destructiva relación sociedad-naturaleza. Pese a que estos fenómenos epidemiológicos son milenarios, adquieren sus especificidades en el marco de los escenarios abiertos por el capitaloceno (concepto introducido por Moore, 2016) y la proclividad al ecocidio.

\section{CONSIDERACIONES FINALES SOBRE LA INVESTIGACIÓN}

John Maynard Keynes escribía, respecto a la relación pensamiento/intereses creados, que «[...] las ideas de los economistas y filósofos políticos, tanto cuando son correctas como erróneas, tienen más poder de lo que comúnmente se cree. De hecho, el mundo está gobernado por ellas. Los hombres prácticos, que se creen exentos de cualquier influencia intelectual, son usualmente esclavos de algún economista difunto» (Keynes, 1936, p. 337). Esta noción esbozada por lord Keynes enfatiza en el carácter estratégico de las ideas y en la gravitación que ejercen en la configuración del poder y de las decisiones. Sin las ideas preconcebidas, para bien o para mal, es imposible tomar decisiones y abrir cursos de acción que le dan forma a la realidad social.

Más aún, que el presente y el destino que se forja la humanidad estén en función de lo que un economista susurre al oído de gobernantes, planificadores y funcionarios nacionales e internacionales, es para llamar la atención y someterlo a reflexión, análisis, escrutinio y deliberación. De ahí que sea posible argumentar que si la ciencia económica no dialoga con otras disciplinas, continuará omitiendo vastas parcelas de la realidad social y no superará su condición de inducido autismo. Si cualquier teoría social, política o económica no comienza por cuestionarse a sí misma en sus fundamentos, postulados, supuestos, contribuciones, alcances y limitaciones, no podrá recrearse ni responder a las grandes preguntas que suscitan los problemas públicos contemporáneos. Además, sin un ejerció del pensamiento crítico sobre sí misma, toda ciencia será un corpus teórico anquilosado, dogmatizado, inerte, petrificado y distante o desanclado del mundo fenoménico y sus contradicciones. Y si ello ocurre, el conocimiento no solo se torna en dogma, sino en una lápida que eclipsa o ciega a la misma academia y a las élites políticas que toman las decisiones públicas.

Haciendo un ejercicio de pensamiento crítico constructivo y sin el mínimo ánimo de demeritar cualquier postura académica, para abrir el ostión de la teoría económica convencional resulta preciso que sus académicos y profesionistas aprendan a dialogar con otras tradiciones de pensamiento (economía política clásica, keynesianismo, institucionalismo, marxismo, historicismo, estructuralismo latinoamericano, regulacionismo, economía social y solidaria, economía feminista, economía de la vida y de los cuidados, etc.) e, incluso, abrevar de los avances 
que desde dentro de su propio paradigma se gestan — pensemos en los aportes neoclásicos de Amartya Sen (1999 y 2009), Joseph E. Stiglitz (2002 y 2006), Dani Rodrik (2007), entre otros-. Sin este diálogo a su interior, serían impensables otros diálogos multidireccionales con disciplinas como la sociología, la ciencia política, las relaciones internacionales, los estudios de área, la historia, la antropología, los estudios críticos del desarrollo, entre otras, que pretenden construir respuestas en torno a los grandes problemas de la humanidad. Es preciso también romper las ataduras de sus supuestos restrictivos y el grillete que impone el individualismo metodológico y el mantra infundado de la escasez. Ante la soberbia, el complejo de superioridad, y las cegueras ideológicas, es necesario anteponer la honestidad, la modestia y la humildad socrática; pues de lo contrario, la sexta extinción perfilada por el colapso climático y la inanición que impone el desempleo masivo, terminarán por lapidar, de manera irreversible, a las sociedades humanas.

Mirar y re(visitar) a los clásicos del pensamiento económico no solo es un imperativo teórico, sino también una urgente necesidad respecto a la construcción de referentes para el ejercicio de la praxis política. Hacerlos dialogar con los teóricos contemporáneos de la ciencia económica es fundamental para reivindicar la vertiente filosófica del conocimiento científico y el abordaje epistemológico y ético en el análisis económico. Sin esa intersección de la filosofía con la ciencia económica, resulta tarea cuesta arriba afinar las miradas interdisciplinarias y abrir los cauces para reflexionar y estudiar el carácter complejo de los procesos sociales contemporáneos y de las distintas crisis que asedian a la humanidad. Las posibilidades de construir soluciones para enfrentar las problemáticas concretas que afectan a los ciudadanos de a pie atraviesan por la capacidad para incorporar la imaginación creadora y el pensamiento crítico en las formas de estudiar la realidad; sin este esfuerzo no solo se petrifica la teoría, sino que clausuramos la misma capacidad para ejercer el pensamiento utópico e imaginar el futuro en tiempos pandémicos de incertidumbre y confusión epocal.

Ex Hacienda de Santa Cruz de los Patos

Estado de México, septiembre de 2020.

\section{REFERENCIAS}

Acosta, A. (2013). El Buen Vivir. Sumak kawsay, una oportunidad para imaginar otros mundos, Barcelona, Icaria Editorial.

Acosta, A. (2014). El Buen Vivir, más allá del desarrollo. En G. C. Delgado Ramos (coord.), Buena Vida, Buen Vivir: imaginarios alternativos para el bien común de la humanidad, Universidad Nacional Autónoma de México (UNAM), 21-60.

Boland, L. A. (1997). Critical economic methodology. A personal odyssey. Routledge.

Enríquez Pérez, I. (2008). La construcción del pensamiento científico en las ciencias físico/naturales y en la economía. Notas para desentrañar la naturaleza epistemológica de las ciencias económicas. Revista Economía, gestión y desarrollo, 6, 39-77.

Enríquez Pérez, I. (2009a). La evolución de las concepciones sobre el desarrollo en el Banco Mundial y su incidencia en América Latina: un panorama general. Revista Nicolaita de Estudios Económicos, $\operatorname{IV}(1), 111-140$. 
Enríquez Pérez, I. (2009b). Los vaivenes teórico/epistemológicos en las ciencias sociales latinoamericanas. Revista Estudios Latinoamericanos, 23, 17-45.

Enríquez Pérez, I. (2010a). La construcción social de las teorías del desarrollo: un estudio histórico/crítico para incidir en el diseño de las políticas públicas. Editorial Miguel Ángel Porrúa y H. Cámara de Diputados.

Enríquez Pérez, I. (2010b). La evolución del pensamiento sobre el desarrollo en el Fondo Monetario Internacional y el Banco Mundial: un análisis comparativo sobre su gravitación en América Latina. En Trayectorias. Revista de Ciencias Sociales, XII(31), 31-60.

Enríquez Pérez, I. (2014). La perspectiva del desarrollo sostenible en el pensamiento del Banco Mundial: la asimétrica simbiosis entre la agenda económica y la agenda ambiental. Realidad económica. Revista de Ciencias Sociales, 287, 118-140.

Enríquez Pérez, I. (2015). Los organismos internacionales y su incidencia en el desarrollo latinoamericano: la gravitación del pensamiento y las estrategias del Banco Mundial en las políticas públicas mexicanas. Universidad Complutense de Madrid, Tesis Doctoral. http://eprints.ucm.es/33678/1/T36554.pdf Enríquez Pérez, I. (2016a). Los senderos de los organismos internacionales en la cooperación para el desarrollo: un panorama general sobre la evolución de las estrategias del Banco Mundial. Revista Análisis político, 29(88), 105-125.

Enríquez Pérez, I. (2016b). Contrapuntos en torno al concepto, metodología y enseñanza de la economía: notas críticas para comprender la construcción y transmisión del conocimiento en las ciencias económicas. Revista Ciencias Económicas, 13(2), 21-48.

Enríquez Pérez, I. (2017). Variaciones en torno a la noción del concepto de desarrollo: notas introductorias para la definición de un constructo con implicaciones teóricas y políticas. Filosofía de la Economía. Revista del Centro de Investigación en Epistemología de las Ciencias Económicas, 6(1), 23-41.

Enríquez Pérez, I. (2018). La incidencia del factor empresarial en la dialéctica desarrollo/subdesarrollo: las racionalidades empresariales y el capital social en los espacios locales/regionales. ICADE. Revista de las Facultades de Derecho y Ciencias Económicas y Empresariales, 104, 203-239.

Enríquez Pérez, I. (2020). La gran reclusión y los vericuetos sociohistóricos del coronavirus: miedo, dispositivos de poder, tergiversación semántica y escenarios prospectivos. Centro de Estudios en Estrategia y Políticas Públicas. https://ceeypp.com/publicaciones/

Freeman, R. B. (1996). Solving the new inequality. Boston Review. A Political and Literary Forum, 21(6), 3-10.

Friedman, M. ([1953] 1967). Ensayos sobre economía positiva. Gredos.

Friedman, M. (1970). The social responsibility of business is to increase its profits. En The New York Times Magazine, september 13. Online: https://www.nytimes.com/1970/o9/13/archives/a-friedman-doctrine-the-social-responsibility-of-business-is-to.html

Furedi, F. ([2003] 1997). Culture of fear. Risk-taking and the morality of low expectation. Continuum.

Gasca Zamora, J. (2014). Gobernanza y gestión comunitaria de recursos naturales en la Sierra Norte de Oaxaca. Revista Región y sociedad, año xxvi, 26(60), 89-120.

Grosfoguel, R. (2005). The implications of subaltern epistemologies for global capitalism: transmodernity, border thinking and global coloniality. En W. I. Robinson and R. Applebaum (eds.), Critical globalization studies. Routledge. 
Grosfoguel, R. (2011). Decolonizing post-colonial studies and paradigms of political-economy: Transmodernity, decolonial thinking and global coloniality. Transmodernity: Journal of Peripheral Cultural Production of the Luso-Hispanic World, 1(1), 1-38.

Keynes, J. M. ([1936] 1984). Teoría general de la ocupación, el interés y el dinero. Fondo de Cultura Económica.

Klein, N. (2013). Dancing the world into being: a conversation with Idle-No-More's Leanne Simpson. En Yes Magazine, March 6. https://www.yesmagazine.org/social-justice/2013/o3/o6/ dancing-the-world-into-being-a-conversation-with-idle-no-more-leanne-simpson/

Lazear, E. P. and Shaw, K. L. (eds.) (2018). Firms and the distribution of income: the roles of productivity and luck. En Journal of Labor Economics, 36(S1), January.

León Rodríguez, M., Gómez Corral, A. y Castro Ponce, M. (2020). SARS-CoV-2: La geometría del enemigo. The Conversation. Academic rigor, journalistic flair, 15 de abril. https://theconversation. com/sars-cov-2-la-geometria-del-enemigo-136302

Mankiw, N. G. ([2006] 2007). El macroeconomista como científico y como ingeniero. Revista Desarrollo Económico, $47(185)$, 3-23.

Marx, K. ([1857] 1989). Introducción general a la crítica de la economía política/1857. Siglo xxi Editores.

Mauss, M. ([1924] 2009). Ensayo sobre el don. Forma y función del intercambio en las sociedades arcaicas. Editorial Katz.

Mauss, M. ([1950] 1971). Sociología y antropología. Editorial Tecnos.

Mignolo, W. (2000). Local histories/global designs: Essays on the coloniality of power, subaltern knowledges and border thinking. Princeton University Press.

Moore, J. W. (2016). Introduction. Antropocene or capitalocene? Nature, history, and the crisis of capitalism. En J. W. Moore (ed.), Antropocene or capitalocene? Nature, history, and the crisis of capitalism (pp. 1-11.). PM Press and Kairos.

Rodrik, D. ([2007] 2011). Una economía, muchas recetas. La globalización, las instituciones y el crecimiento económico. FCE.

Samuelson, P. A. y Nordhaus, W. D. ([2006] 1985). Economía. Editorial McGraw Hill/Interamericana.

Sen, A. K. (1999), Development as freedom. Oxford University Press.

Sen, A. K. (2009). The idea of justice. Belknap Press of Harvard University Press.

Simpson, L. B. (2014). Mohawk interruptus: Political life across the borders of Settler States. Duke University Press.

Stiglitz, J. E. (2002). Globalization and its discontents. W. W. Norton \& company, Inc.

Stiglitz, J. E. (2006). Making globalization work. W. W. Norton \& company, Inc. 